$\xi=-1$

\title{
Raspberry Pi-Based Farming Automation and Monitoring System using Automatic Weather System (AWS) (Case Study: Chili Plants)
}

\author{
Erfan Rohadi ${ }^{1}$, Raka Admiral Abdurrahman ${ }^{2 *}$, Ekojono $^{3}$, Rosa Andrie Asmara ${ }^{4}$, Indrazno Siradjuddin ${ }^{5}$, Ferdian $^{2}$ \\ Ronilaya $^{6}$, Awan Setiawan \\ 1,2,3,4 Departments of Information Technology, State Polytechnic of Malang, Malang, Indonesia \\ ${ }^{5,6,7}$ Departments of Electrical Engineering, State Polytechnic of Malang, Malang, Indonesia \\ *Corresponding Author E-mail: raka.flyhigh@gmail.com
}

\begin{abstract}
Recently, The Internet of Things (IoT) has been implemented and become an interesting topic for discussion. IoT is a method that aims to maximize the benefits of Internet connectivity to transfer and process data or information through an internet network wirelessly, virtual and autonomous. One of the IoT's utilization is automation system. The automation system generally uses a timer for the plant watering process. The use of timers aims to water the plants routinely without human assistance. The development of this automation system begins with the making of the prototype of chili land in the field $5 \times 2.5$ meters, then compile the required components and how it works. Further programming of sensors to Raspberry $\mathrm{Pi}$ as a controller in the system based on the conditions that have been set and changes in temperature received by the sensor. As a result, the system has been successfully done automatic watering, both on a regular basis (at 06.00 and 18.00) and cooling watering. Cooling is done if the temperature exceeds more than 30 degrees Celsius. The automation system promises to be applied to the utilization of land around the house.
\end{abstract}

Keywords: Automation; Chili Plants; Internet of Things; Raspberry Pi; Sensors

\section{Introduction}

Internet of Things, or abbreviated as IoT [11], has experienced very rapid development and has become a topic worthy of discussion and development today. Given the statistics reported by IHS Markit ${ }^{\circledR}$ in 2015 , there were 15.4 billion devices connected to each other through the Internet network. This amount is expected to continue to increase to reach 30.7 billion devices connected by 2020 and 75.4 billion devices by 2025 [1]. IoT itself is a method that aims to maximize the benefits of internet connectivity to transfer and process data or information through an internet network wirelessly, virtually and autonomously. Utilization of the IoT method itself has begun to enter various fields, for example in the fields of education, telecommunications, agriculture, plantations, and so on.

Chili is a seasonal horticulture plant, meaning that it is a plant source of vitamins, mineral salts, etc. which is consumed from the part in the form of fruit (chili), less than one year old, not in the form of trees or clumps but spreading and trunking softly [2]. In addition, Chili is one of the most popular agricultural commodities in Indonesia because in general the Indonesian people like spicy food. On the other hand, current changes in lifestyle and the development of the culinary industry that continues to increase also affect the demand for chili. Based on a survey conducted by BPS, the production of cayenne pepper continues to increase. In comparison, the production of chili pepper in Indonesia in 2014 amounted to 0.800 million tons and in 2013 amounted to 1.012 tons. This means that it has increased by 6.09 percent [3]. Whereas for consumption of red chili in Indonesia in 2014 reached approx- imately $2.93 \mathrm{~kg}$ per capita per year and in 2013 it reached $2.89 \mathrm{~kg}$ per capita per year. This means that it has increased by $1.45 \%$ [4]. The in-crease in production is in line with current culinary developments which mostly use chili as the main ingredient. However, as the development of technology progresses as it is now strongly recommended that progressive and progressive agriculture requires a new innovation that is urgently needed to reach and adapt to such rapid changes. Another result of the analysis shown by BPS states that chili farmers who have less than 1 (one) hectare of arable land produce less income because production costs are not proportional to the cost of income [5].

Starting from this problem, an Automation System for Plantation and Weather Monitoring will be built using Automatic Weather System (AWS) [9]-[10] Based on Raspberry Pi. This application helps real-time monitoring of the condition of the chili planted. In addition, to facilitate users in monitoring the plants, information will be displayed relating to the weather outlook in the next few days so that action can be taken quickly because the chili plants are very sensitive to climate change. It is expected that this system can help small-scale chili farmers to produce large amounts of chili and encourage young people to grow crops with the latest technology.

\section{Previous Research}

An in 2013, Venkata Naga displayed paper entitled "Micro Controller Based Automatic Plant Irrigation System". Making an automatic plant irrigation watering system using temperature and humidity sensor. The sensor connected internal ports of microcon- 
troller via comparator. If there is a change in temperature and humidity in surroundings, thus the sprinkler is activated [12].

In 2014, Viktorianus Ryan Juniardy displayed paper entitled "Prototype Automatic Water Sprayer Tools in Garden palm Seeding Based on Humidity Sensors and ATMega8 AVR Micro controller". Making an automatic plant watering system using soil moisture sensor. With the variable humidity of the planting media as a watering timer, it is made a prototype of a water sprayer that cando watering automatically. This automatic water spray prototype is equipped with four soil moisture sensors which are used to read the moisture values of oil palm growing media at once functions as a system input, LCD as a media monitoring system performance, and relay which functions to turn on and off the water pump connected to the pipe installation watering the planting media [13].

Also, in 2014, Roneel V. Sharan displayed entitled "Development of a Remote Automatic Weather Station with a PC- based Data Logger". Develop a prototype weather station to measure the following weather data: air temperature, relative humidity, dew point, wind speed, and rainfall. The weather station, which has been designed for remote operation, performs automatic or unmanned measurements of weather data and transmits it wirelessly to a PC for logging and display by means of a graphical user interface. Experimental results show that the measured data is quite consistent with those obtained by similar weather measurement devices [14].

In 2016, Drashti Divani displayed paper entitled "Automated Plant Watering System". Making an automatic plant watering system using soil moisture sensor. People always forget watering plant in the afternoon. This paper aims to implement a simple system, using automatic irrigation, watering a small potted plant or crop with minimal human intervention [15].

\section{Research Methodology}

This research was carried out in accordance with the stages in accordance with the Fishbone Diagram shown in Figure 1 below.

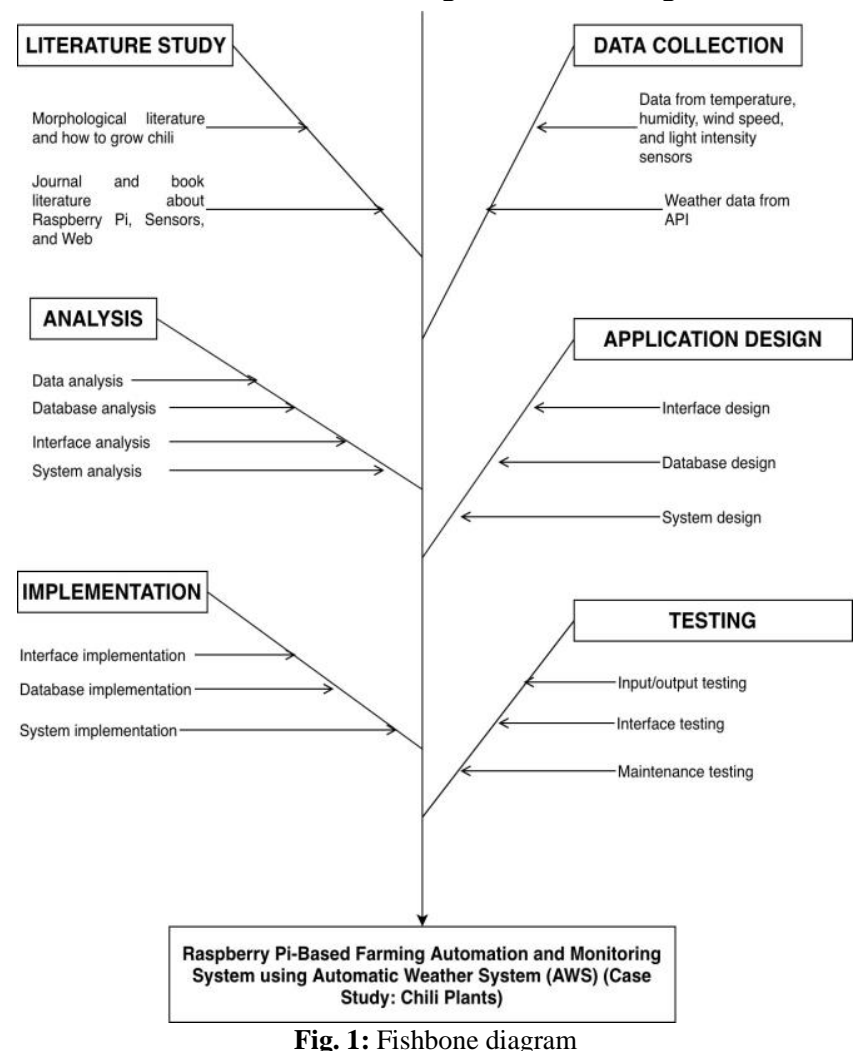

\subsection{Planting Layout}

The design of the land to be used for planting the cayenne pepper plant has a size of $5 \mathrm{~m} \times 2.5 \mathrm{~m}$ with a total area of $12.5 \mathrm{~m}^{2}$. The land will be planted with cayenne pepper for about 40 plants. The specifications of the land to be used are shown in Figure 2 below.
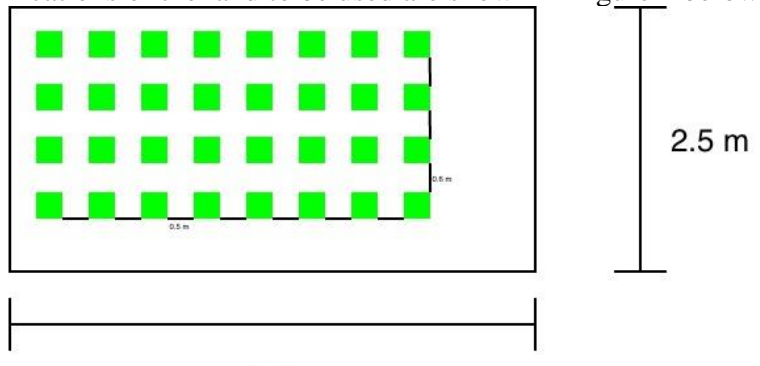

$$
5 \mathrm{~m}
$$

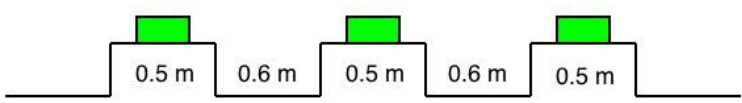

Fig. 2: Planting layout for chili plants

\subsection{Hardware Design}

Hardware design aims to plan or design hardware in accordance with the specifications and flow of the system to be created. Hardware design is made in the form of block diagrams which consist of the arrangement of tools and systems in general, as illustrated in Figure 3.

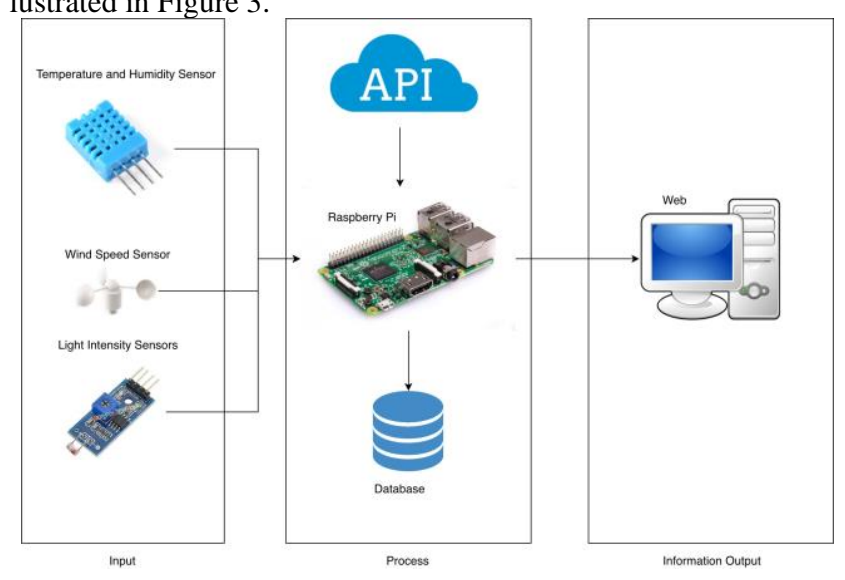

Fig. 3: Hardware design

In this automation system, sensors take data from the temperature sensor, air humidity, wind speed, and light intensity. Temperature and humidity sensors will measure the temperature in the field to be worked on, while the light intensity sensor will measure the intensity of sunlight in the field to be worked on. Then, after the sensors get all the measurement data, the data will be entered into the database contained in the Raspberry Pi. The sensor monitoring data contained in the Raspberry Pi will be compared with data from the OpenWeatherMap API. The data is compared to the aim to check whether the data from the sensors is accurate or not while determining the weather in the area (on the land). After the data from the sensors and APIs have been put together, then the watering pattern of chili will be determined in the arable land based on temperature, humidity, and sunlight intensity, while for wind speed will determine when the paranet will be closed. 


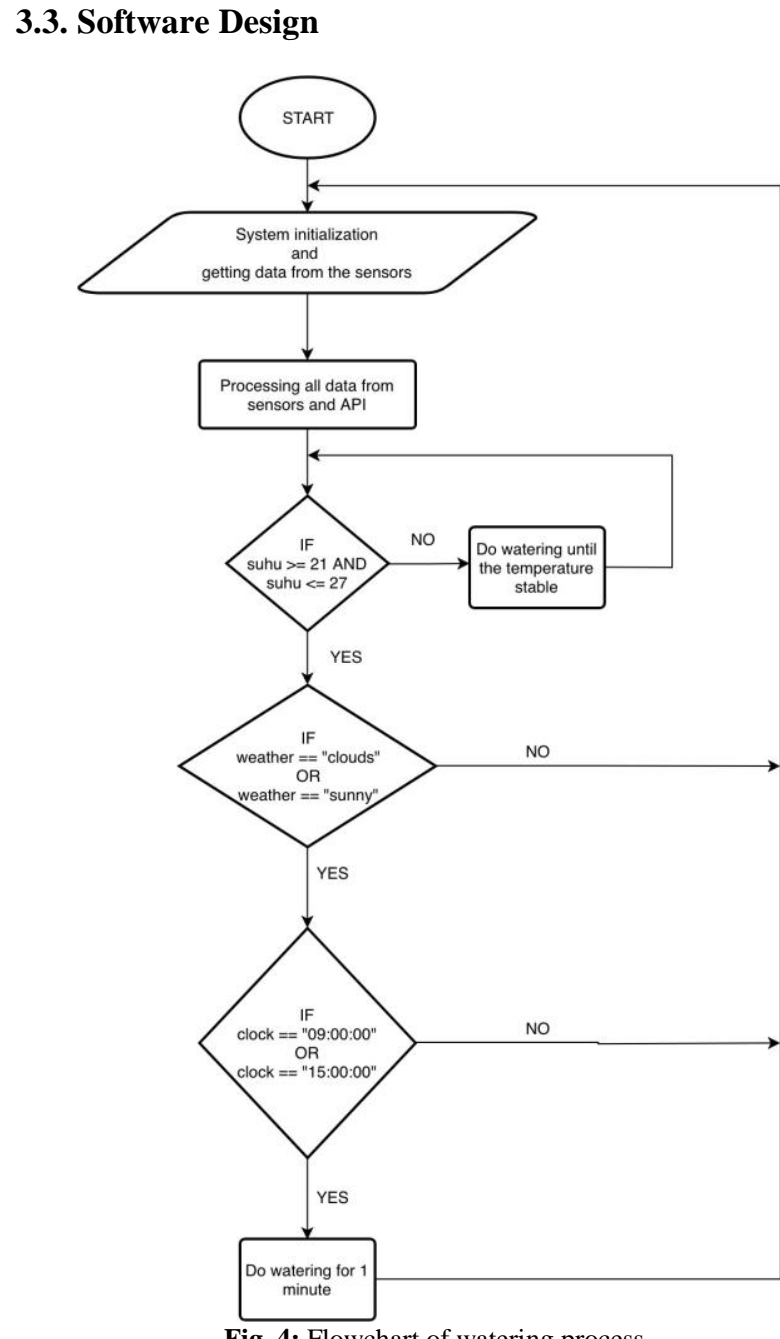

Fig. 4: Flowchart of watering process

When the system is run, the system first takes data from the temperature sensor, air humidity, wind speed, and light intensity. Then, the data is combined with data from the OpenWeatherMap API. Furthermore, it will be checked whether the ambient temperature is between $21 \square \mathrm{C}$ to $30 \square \mathrm{C}$. If it meets the temperature requirements, it will be checked again if the weather is sunny or cloudy. If the weather is sunny (cloudy), then watering is done twice a day every morning (6:00 a.m.) and afternoon (6:00 p.m.) to avoid excessive evaporation and more optimal plant growth [6]. If the weather is rainy, there is no need to water. If the temperature is more than $30^{\circ} \mathrm{C}$, it will be cooled by water to a temperature in the stable cultivated land.

\section{Implementation}

\subsection{Land Implementation}

The land used to grow the chili plant has an area of $12.5 \mathrm{~m}^{2}$ with a land length of $5 \mathrm{~m}$ and a width of $2.5 \mathrm{~m}$. The land area is made up of 20 beds with $60 \mathrm{~cm}$ between plants and $50 \mathrm{~cm}$ between rows. After the chili field is installed, then install the pipes and cut them with a distance equal to the distance between the cayenne pepper plants, as illustrated in Figure 5 below.

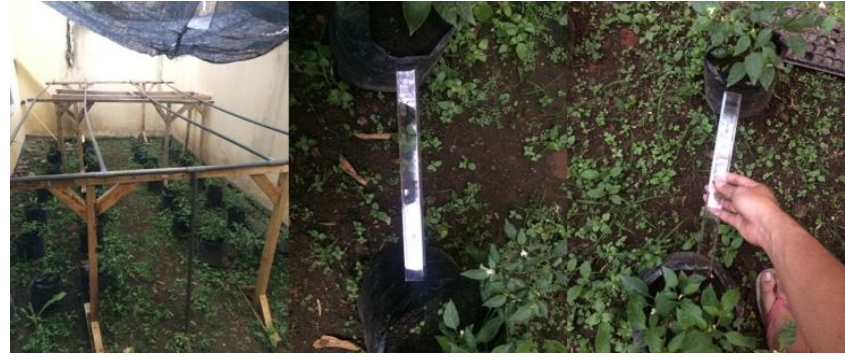

Fig. 5: Field implementation

\subsection{System Implementation}

The system is created after each hardware and software has been installed properly. This system will monitor based on parameters of temperature, humidity, wind speed, and light intensity. All these parameters will be monitored through a web-based system on the local network and the internet. Then, this system will carry out regular watering and cooling automation. Regular watering is carried out twice a day every morning (6:00 a.m.) and evening (6:00 p.m.) to avoid excessive evaporation and more optimal plant growth [6]. Whereas for cooling watering is done if the temperature in arable land is more than $30 \square \mathrm{C}$.

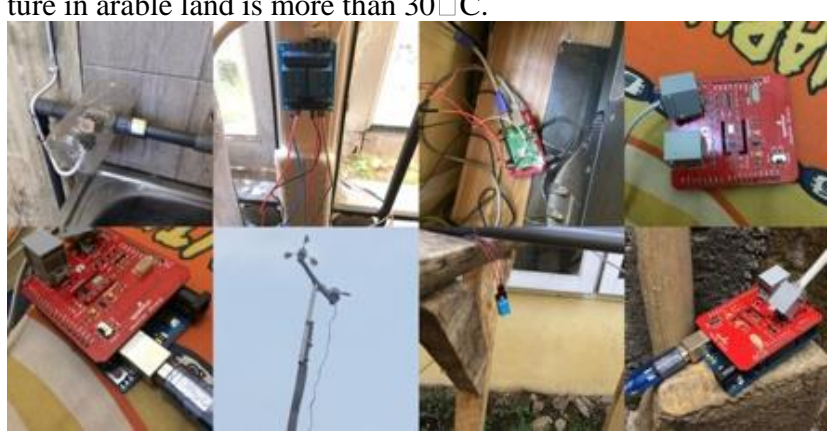

Fig. 6: Implementation of relay and temperature, humidity, wind speed and light intensity sensors

In addition to the automation system for regular watering, this system also automates if the sensors installed on the land are in error or do not read the parameters. The data taken is the value of each sensor on a week back, then find the appropriate value, and an action will be performed. The action is temporary until the sensor has been repaired.

\section{Results}

\subsection{Prototype Implementation}

First, we collected the received data from the sensor that is from air temperature sensor, humidity sensor, wind speed sensor, and light intensity sensor, then the data combined with API from OpenWeatherMap to ensure the data is accurate or not. After the all data from the sensor and data from API collected, the data is stored in database MySQL in Raspberry Pi. After the data is stored, the data analysis will be carried out. The data analyzed is the value of the sensor itself and the time of data collection. So, we can monitor the condition of the chili pepper plant in real-time. If the temperature surroundings between $21 \square \mathrm{C}$ to $30 \square \mathrm{C}$. If it meets the temperature requirements, it will be checked again if the weather is sunny or cloudy. If the weather is sunny (cloudy), then watering is done twice a day every morning (6:00 a.m.) and afternoon (6:00 p.m.) to avoid excessive evaporation and more optimal plant growth [5]. If the weather is rainy, there is no need to water. If the temperature is more than $30^{\circ} \mathrm{C}$, it will be cooled by water to a temperature in the stable cultivated land. The data of all sensor can be displayed as Figure 7 below. For the trend analysis for sensor data trends is explained in sub-chapter 5.2 through 5.5. 


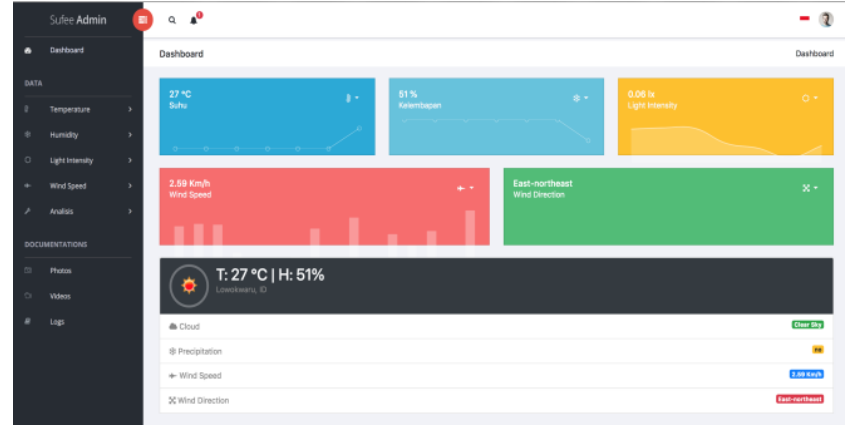

Fig. 7: Dashboard website

\subsection{Air Temperature Sensors}

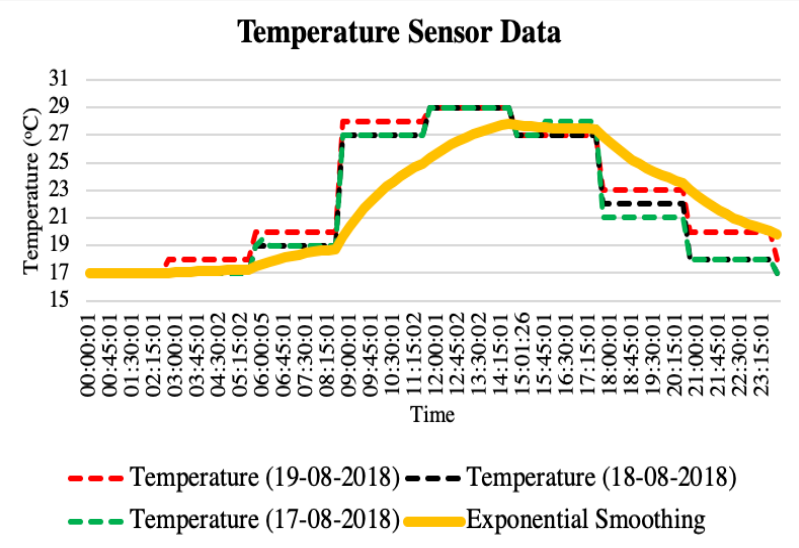

Fig. 8: Graphic of temperature sensor data reading

The graph above explain the air temperature data taken for three days, the red color chart with dashed lines represents the temperature sensor data taken on August 19, 2018, the black color graph with the dashed line represents the temperature sensor data taken on the 18th August 2018, and the green chart with dotted lines describes the temperature sensor data taken on August 17, 2018. The orange color chart is an exponential smoothing [6]-[8] result of the average of the three-temperature data. From the graph shows that the temperature data have the same trend.

\subsection{Air Humidity Sensors}

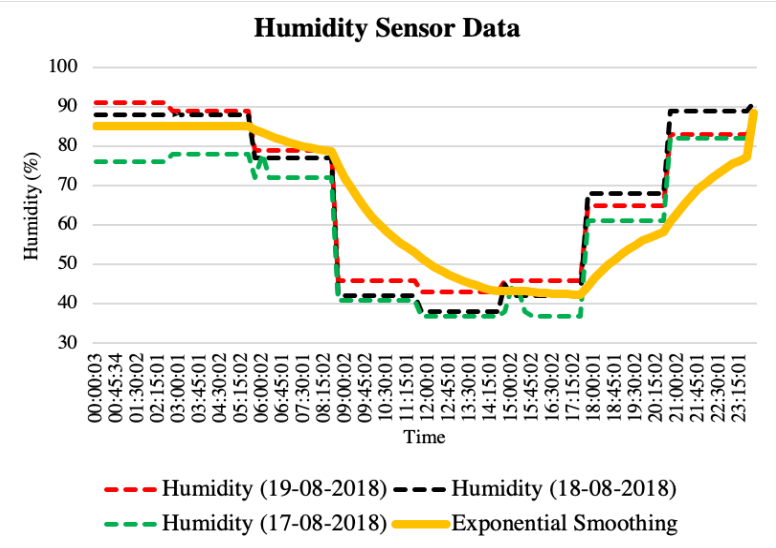

Fig. 9: Graphic of humidity sensor data reading

The graph above illustrates the data of air humidity taken for three days, the red color chart with dotted lines describes the data of air humidity sensor taken on August 19, 2018, the black color graph with dashed lines describes the data of air humidity sensor taken on dated August 18, 2018, and the green graph with dotted lines illustrates the data on air humidity sensors taken on August 17, 2018. The orange color chart is an exponential smoothing [6]-[8] result of the average of the three-humidity data. From the graph shows that the humidity data have the same trend.

\subsection{Wind Speed Sensors}

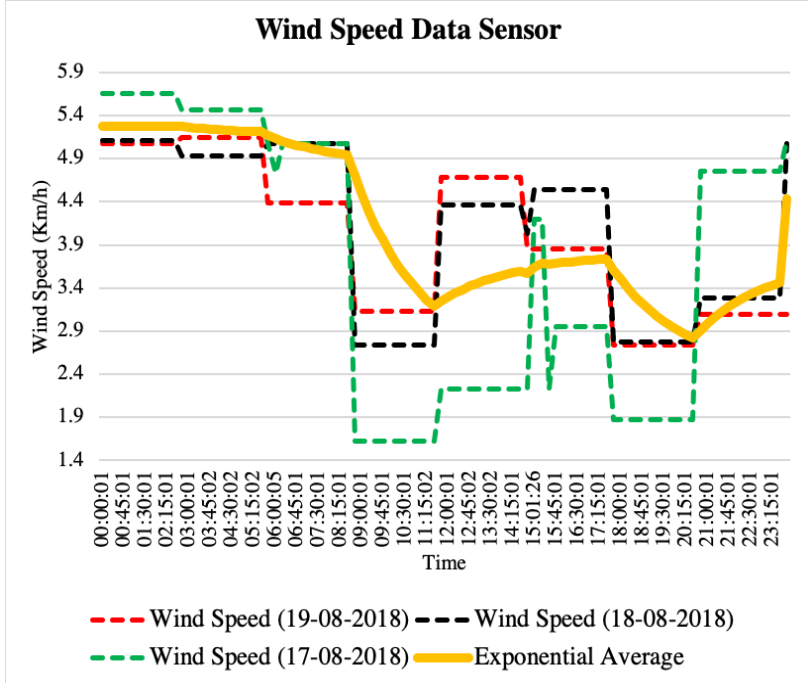

Fig. 10: Graphic of wind speed sensor data reading

The graph above illustrates the wind speed data taken for three days, the red graph with the dashed line illustrates the wind speed sensor data were taken on August 19, 2018, the black color graph with the dashed line represents the wind speed sensor data taken on dated August 18, 2018, and the green graph with dashed lines describes the wind speed sensor data taken on August 17, 2018. The orange color chart is an exponential smoothing [6]-[8] result of the average of the three wind speed data. From the graph shows that the wind speed data has the same trend.

\subsection{Light Intensity Sensors}

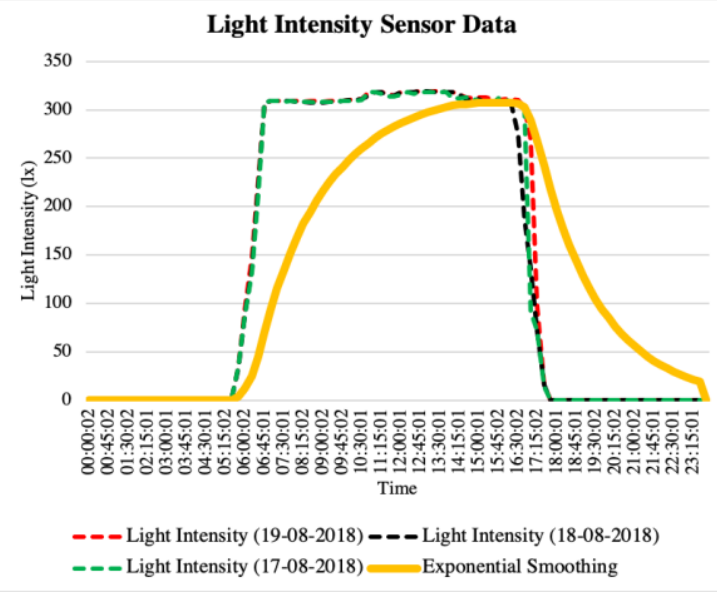

Fig. 11: Graphic of light intensity sensor data reading

The graph above illustrates the data of light intensity taken for three days, the red graph with the dashed line illustrates the light intensity sensor data were taken on August 19, 2018, the black graph with the dashed line illustrates the light intensity sensor data taken on dated August 18, 2018, and the green graph with dashed lines shows the light intensity sensor data taken on August 17, 2018. The orange color chart is an exponential smoothing [6]-[8] result of the average of the three light intensity data. From the graph shows that the wind speed data has the same trend. 


\subsection{Comparison with Related Works}

Table 1: Comparison with other research

\begin{tabular}{|l|l|l|}
\hline Related Works & Limitations & Our System \\
\hline MCAPIS [12] & $\begin{array}{l}\text { Microcontroller AT- } \\
\text { mega328p can't store } \\
\text { the data into DB } \\
\text { MySQL directly. }\end{array}$ & $\begin{array}{l}\text { We use the Raspberry Pi to } \\
\text { ease storing DB into } \\
\text { MySQL directly from Py- } \\
\text { thon. This aims to ease the } \\
\text { programmer maintain all } \\
\text { data from the sensors }\end{array}$ \\
\hline PAWSTGS [13] & $\begin{array}{l}\text { Using LCD to display } \\
\text { output data. Which is } \\
\text { we must go to land to } \\
\text { see the sensor value. }\end{array}$ & $\begin{array}{l}\text { We use the web-based } \\
\text { monitoring system. So, we } \\
\text { don't need to go to land to } \\
\text { monitor the sensor value and } \\
\text { land condition in real-time. }\end{array}$ \\
\hline DRAWS [14] & $\begin{array}{l}\text { Develop a weather } \\
\text { monitoring system } \\
\text { only to monitor the } \\
\text { current weather }\end{array}$ & $\begin{array}{l}\text { We develop a weather moni- } \\
\text { toring system for indicators } \\
\text { of watering plants. If rain is } \\
\text { predicted, watering is not } \\
\text { necessary. }\end{array}$ \\
\hline APWS [15] & $\begin{array}{l}\text { Only using soil mois- } \\
\text { ture sensor to deter- } \\
\text { mine when the plant } \\
\text { is need to watering or } \\
\text { not }\end{array}$ & $\begin{array}{l}\text { We add more sensors like } \\
\text { temperature, humidity, wind } \\
\text { speed, and light intensity } \\
\text { sensor. We also added a } \\
\text { module called Automatic } \\
\text { Weather System (AWS) to } \\
\text { prevent watering the plant if } \\
\text { rain is predicted. }\end{array}$ \\
\hline
\end{tabular}

\section{Conclusion}

The proposed of Raspberry Pi-Based Farming Automation and Monitoring System using Automatic Weather System (AWS) has been presented. The test results show that all sensors function properly, data from all four sensors are read and processed in Raspberry Pi to run the chili plant maintenance automation system. This Automation systems developed by testing promising chili plants to be applied to the use of limited land especially in urban area.

\section{Future Research}

Our implemented system not only tries to make automatic plant watering system on limited land, but also serve the academic community to learn about Internet of Things (IoT) in agriculture. The main function of this system is to monitor the chili pepper growth using digital approached. Since our system is done remotely, the future research is adding monitoring and automatic watering system for more extensive land. Also, we add implementation to mobile apps like Android and iOS to facilitate the community in monitoring all available land.

\section{Acknowledgement}

We are forever grateful to our beloved institution, State Polytechnic of Malang for giving us the opportunity to build this project from zero. Also, we are thankful for all team members good work and our beloved friends on campus to support us building this project.

\section{References}

[1] K. Claveria, "13 Stunning Stats on The Internet of Things", 28 April 2017. [Online]. Available: https://www.visioncritical.com/internet-of-things-stats/. [Accessed: 16 April 2018].

[2] Badan Pusat Statistik, "Istilah Pertanian dan Pertambangan", [Online]. Available: https://www.bps.go.id/subject/55/hortikultura.html\#subjekViewTab 1. [Accessed: 16 April 2018].
[3] "Produksi Cabai Besar, Cabai Rawit, Dan Bawang Rawit Tahun 2014”, Berita Resmi Statistik, (2015), pp: 1-2, Jakarta: Badan Pusat Statistik.

[4] Suwandi, et.al, "Outlook Cabai”, (2016), pp: 17-18, Jakarta: Pusat Data dan Sistem Informasi Pertanian Sekretariat Jenderal Kementerian Pertanian.

[5] Winarno F.G, et.al, "Produksi dan Perdagangan Cabai", Cabai Potensi Pengembangan Agrobisnis dan Agroindustri, (2017), pp: 18 19, Jakarta: PT. Gramedia Pustaka Utama.

[6] S Janardhanarao, et.al, "Speech intelligibility improvement based on adaptive exponential smoothing factor", Vol. 7, No 2.8, (2018), pp: 456-460, available online: https://www.sciencepubco.com/index.php/ijet/article/view/10483/3 792, last visit: 30.10 .2018

[7] Nur Adilah Abd Jalil, et.al. "Electricity Load Demand Forecasting Using Exponential Smoothing Methods", Vol. 22, No. 11, (2013), pp: 1540-1543, available online: https://pdfs.semanticscholar.org/d938/01c6d70a050d126f30d973b1 398c0c8b0775.pdf, last visit: 30.10.2018

[8] Dazhi Yang, et.al. "Forecasting of global horizontal irradiance by exponential smoothing, using decompositions", Vol. 81, (2015), pp 111-119, available online: https://www.sciencedirect.com/science/article/abs/pii/S0360544214 013528, last visit: 30.08 .2018

[9] Hobby, M., et.al. "The Fennec Automatic Weather Station (AWS) Network: Monitoring the Saharan Climate System”, Vol. 30, No. 4, (2013), pp: 709-724, available online: https://journals.ametsoc.org/doi/full/10.1175/JTECH-D-12-00037.1, last visit: 30.10 .2018

[10] J. Kaivosoja, et.al. "Automatic control of farming opera-tions based on spatial web services", Vol. 100, (2014), pp: 110-115, available online:

https://www.sciencedirect.com/science/article/pii/S0168169913002 731, last visit: 30.08 .2018

[11] Jayavardhana Gubbi, et.al. "Internet of Things (IoT): A vision, architectural elements, and future directions", Vol. 29, No. 7, (2013), pp: 1645-1660, available online: https://www.sciencedirect.com/science/article/pii/S0167739X13000 241, last visit: 30.10 .2018

[12] Gunturi, Venkata Naga Rohit, "Micro Controller Based Automatic Plant Irrigation System", International Journal of Advancements in Research \& Technology, Vol. 2, No. 4, (2013), pp. 194-198, available online: http://retawprojects.com/uploads/Micro-ControllerBased-Automatic-Plant-Irrigation-System.pdf, last visit: 7.11.2018

[13] Viktorianus Ryan Juniardy, Dedi Triyanto, and Yulrio Brianorman, "Prototype Automatic Water Sprayer Tools in Gardenpalm Seeding Based on Humidity Sensors and ATmega8 AVR Microcontroller", Jurnal Coding Sistem Komputer Untan, Vol. 2, No. 3, (2014), pp. 1-10, available online: http://jurnal.untan.ac.id/index.php/jcskommipa/article/view/7614/7 733, last visit: 7.11.2018

[14] Sharan, Roneel V., "Development of a Remote Automatic Weath-er Station with a PC- based Data Logger", International Journal of Hybrid Information Technology, Vol. 7, No. 1, (2014), pp. 232-240, available online: http://www.sersc.org/journals/IJHIT/vol7_no1_2014/19.pdf, last visit: 7.11 .2018

[15] Divani, Drashti, “Automated Plant Watering System", International Conference on Computation of Power, Energy Information and Communication (ICCPEIC), pp. 180-182, available online: https://ieeexplore.ieee.org/abstract/document/7557245, last visit: 7.11.2018 